S Research S Suare

\title{
Assessment of Parasympathetic Cardiovascular Activity in Primary Open Angle Glaucoma
}

Oluwaseun Olaniyi Awe ( $\square$ linkseunawe@gmail.com )

Obafemi Awolowo University Faculty of Clinical Sciences https://orcid.org/0000-0002-8701-707X

\section{Oluwadare Ogunlade}

Obafemi Awolowo University Faculty of Basic Medical Sciences

Bernice Oluwakemi Adegbehingbe

Obafemi Awolowo University Faculty of Clinical Sciences

\section{Research Article}

Keywords: glaucoma, cardiac autonomic function, Ewing's test, Valsalva manoeuvre, blood pressure

Posted Date: August 6th, 2021

DOI: https://doi.org/10.21203/rs.3.rs-772258/v1

License: () (1) This work is licensed under a Creative Commons Attribution 4.0 International License.

Read Full License

Version of Record: A version of this preprint was published at International Ophthalmology on November 5th, 2021. See the published version at https://doi.org/10.1007/s10792-021-02097-1. 


\section{Abstract}

\section{Purpose}

To describe the pattern of quantitative parasympathetic cardiovascular autonomic function among patients with normal-tension glaucoma (NTG) and high-tension primary open-angle glaucoma (HTG) patients.

\section{Methodology}

This was cross-sectional study of ninety-two subjects enrolled into three groups: HTG (31 patients), NTG (31 patients) and Control (30 patients). All the participants had anthropometric assessment, ophthalmic examination, baseline cardiovascular examination and the three parasympathetic components of Ewing's battery of autonomic cardiovascular function tests namely heart rate (HR) response to deep breathing, HR response to Valsalva manoeuvre and HR response to standing.

\section{Result}

The baseline PR intervals were significantly prolonged in HTG $(0.18 \pm 0.03 \mathrm{sec})$ and NTG $(0.18 \pm 0.04 \mathrm{sec})$ groups compared with control $(0.15 \pm 0.03 \mathrm{sec})(p=0.008)$. The HTG group had a significantly longer mean RR interval $(1.09 \pm 0.17 \mathrm{sec})$ than the NTG group $(1.03 \pm 0.20 \mathrm{sec})$ and control $(0.97 \pm 0.17 \mathrm{sec})$ during the expiratory phase of the HR response to deep breathing test $(p=0.037)$. The HTG group also had significantly longer mean RR intervals around the 15th beat $(p=0.033)$ and 30th beats $(p=0.202)$ poststanding during the HR response to standing test. The HR response to Valsalva manoeuvre test showed a significantly higher mean Valsalva ratio in the NTG group $(1.65 \pm 0.48)$ compared to the HTG group (1.45 $\pm 0.31)$ and control $(1.43 \pm 0.25)(p=0.034)$.

\section{Conclusion}

This study demonstrated that normal-tension and high-tension primary open-angle glaucoma have higher parasympathetic cardiovascular activity than normal individuals.

\section{Introduction}

Glaucoma is the leading cause of irreversible blindness worldwide, affecting more than 64.3 million people worldwide in 2013 and projected to rise to 76 million by year 2020 [1]. Glaucoma is considered to result from abnormal physiology in the optic nerve head that interacts with the level of intraocular pressure (IOP), with the degree and rate of damage depending on the intraocular pressure (IOP) and presumably the degree of abnormal physiology [2]. Although intraocular pressure (IOP) remains an important risk factor for glaucoma, it is clear that other factors can also influence disease development and progression.

The autonomic nervous system (ANS) is vital to the control of numerous physiologic processes across many major organ systems. It functions continuously to regulate various systems such as the cardiovascular, gastrointestinal, urinary system, and the skin. Since the ANS influences the function of 
several systems and organs in the body, dysfunction of the ANS can present with symptoms across various system-organs with considerable impact on organ function and homeostatic control. An increasing number of disease conditions have been shown to either cause or are associated with autonomic dysfunction across various organs and systems in the human body [3]. The eye, an organ of sight, has a rich supply of innervation from the autonomic nervous system responsible for many physiologic ocular functions and processes such as pupil size, pupillary reaction, accommodation, intraocular pressure (through its involvement in aqueous humour production and outflow process) and regulation of ocular blood flow [4].

The ocular projections of the autonomic nervous system influence numerous functions of the eye. The autonomic nervous system has been linked to glaucoma based on its projections to various ocular structures and remarkably, many anti-glaucoma medications act by modulating autonomic system receptors located on relevant ocular tissues involved in aqueous humour dynamics. Iris and ciliary muscle contraction can influence aqueous humour outflow; autonomic regulation of ciliary body blood vessels and the ciliary epithelium is an important determinant of aqueous humour formation; autonomic regulation of the trabecular meshwork and episcleral blood vessels is an important determinant of aqueous humour outflow and alterations in choroidal blood flow will cause changes in IOP $[4,5]$. The vasculature is innervated by vasodilatory (parasympathetic) fibres from the pterygopalatine ganglion, and by vasoconstrictive (sympathetic) fibres from the superior cervical ganglion.

Studies have provided evidence of disturbed autoregulation in glaucoma patients not only at the ocular level but also at the systemic level. Some systemic circulatory abnormalities have also been linked to ocular circulatory abnormalities with an effect on disease progression [6, 7]. Dysregulation of the ocular circulation appears to be closely related to systemic vascular dysregulation [8-12]. Since, autonomic innervation to the eye is majorly parasympathetic, we hypothesized that abnormality of parasympathetic regulation is associated with primary open angle glaucoma.

This study aims to describe the pattern of quantitative parasympathetic cardiovascular autonomic function among patients with normal-tension glaucoma (NTG) and high-tension primary open-angle glaucoma (HTG) patients.

\section{Methods}

\section{Participants}

This was a cross-sectional study carried out among 3 study groups. The groups were high-tension primary open-angle glaucoma (HTG), normal-tension glaucoma (NTG) and healthy control. Enrolled participants were consenting individuals aged 18 years or more that presented at the outpatient clinics. Participants enrolled in the HTG and NTG groups were patients identified as having glaucomatous cupping of the optic disc, open anterior chamber angles and visual field defects consistent with the diagnosis of glaucoma. All glaucoma patients had central corneal thickness (CCT) assessment. Classification as HTG was based on pre- and post-CCT corrected intraocular pressure (IOP) measurements consistently above $21 \mathrm{mmHg}$ with 
applanation tonometry while classification as NTG was based on pre- and post-corrected IOP measurements consistently less than or equal to $21 \mathrm{mmHg}$ in treatment naïve patients. Control subjects were age and sex-matched healthy individuals with a normal ocular examination (fundus assessment, IOP measurement and visual fields). All participants had best corrected visual acuity of at least $6 / 18$ in the better eye and near vision of at least N8. Exclusion criteria are listed in Table 1. Ethical approval was obtained from the Ethics \& Research Committee of Obafemi Awolowo University Teaching Hospitals Complex, lle-Ife. Written informed consent was obtained from each subject. Recruitment into the study and all procedures were conducted in accordance with the tenets of the Declaration of Helsinki.

Table 1

Exclusion criteria

\section{Ocular}

Refractive error $> \pm 3 \mathrm{DS}$ and/ or $> \pm 1 \mathrm{DC}$

$\mathrm{IOP}>30 \mathrm{mmHg}$

Visually-disabling cataract or any other media opacities impairing near vision

History of intraocular surgery

Any form of retinal or neuro-ophthalmic disease affecting the ocular vascular system

Closed/ narrow iridocorneal angles

Evidence of secondary glaucoma: e.g. pseudoexfoliation, pigmentary dispersion, uveitis

Any form of retinal or neuro-ophthalmological disease that could result in visual field defects

Systemic

Smokers

History of cardio- or cerebro-vascular diseases (coronary artery disease - CAD, heart failure, arrhythmia, stroke, transient ischaemic attacks)

Peripheral vascular disease

Severe dyslipidaemia (defined as plasma triglycerides $>6.00 \mathrm{mmol} / \mathrm{L}$ or cholesterol levels $>$ $7.00 \mathrm{mmol} / \mathrm{L}$ )

diabetes, as well as other metabolic disorders or chronic diseases that required treatment.

Medications

Anticholinergic, antidepressant, antihistamine and over-the-counter cough and cold medication, antipsychotics, sympathomimetic ( $\mathrm{a}$ - and $ß$-agonists) and parasympathomimetic agents.

Others: Caffeine and alcohol consumption in the preceding one week

State all abbreviations

Cardiac Autonomic Function Tests 
Baseline anthropometric and cardiovascular assessment and the non-invasive cardiac reflex tests of parasympathetic function described by Ewing et al[13] were conducted under controlled ambient temperature and ventilation in a dedicated research room. The three parasympathetic function tests were carried out in the following order: Heart rate response to deep breathing, heart rate response to Valsalva manoeuvre and heart rate response to standing. A rest period of 5 minutes was observed in between tests. Tests were conducted at least 2 hours after the last application of anti-glaucoma medication.

Continuous recording of electrocardiogram (ECG) for heart rate was obtained using the lead II of a Dongjiang ECG-32A machine, CMICS Medical Instrument Co. Limited, Guangdong, China. All the study procedures including cardiovascular autonomic function tests were carried out in the morning between 8:00 am and 12-noon local time, after carefully educating the participants about the testing procedures.

\section{Statistical Analysis}

Data were analysed with IBM SPSS for Windows software version 25 (SPSS Inc., Armonk, NY). Data were described by mean, standard deviation and range for quantitative variables. Chi-square test was used to assess the relationship between categorical variables while ANOVA and Tukey posthoc tests were used as appropriate to determine the difference of continuous variables between the study groups and $p$-value less than 0.05 was considered statistically significant.

\section{Results}

The study enrolled 92 participants consisting of 31 in the HTG group, 31 NTG and 30 Control. The overall mean age of subjects was $56.9 \pm 13.9$ years. the mean age of the HTG $(61.9 \pm 9.9$ years $)$ was higher than that of NTG $(54.8 \pm 11.9$ years; $p=0.013)$ and Control groups $(53.8 \pm 15.7$ years; $p=0.019)$ while there was no significant difference between the NTG group versus Control group. The HTG group expectedly had a significantly larger mean vertical cup-disc ratio (VCDR) and higher mean intraocular pressure (IOP) than the Control group while the NTG group had a significantly larger mean VCDR but similar mean IOP compared to the Control group (Table 2). The distribution of systemic comorbidity and oral medications use was similar across the study groups (Table 3). The mean resting PR interval of the HTG and NTG group was significantly longer than in the Control group (Table 4). Further analysis showed that the PR interval for subjects on topical beta-blockers $(n=26)$ in the HTG and NTG groups was not significantly different from that of non-users $(n=32)(0.18 \pm 0.04$ seconds versus $0.18 \pm 0.03$ seconds; $p=0.951)$. Seven subjects had sinus arrhythmia during baseline ECG recording (Control 1, HTG 1, NTG 7). The results of parasympathetic function tests are presented in Table 5. 
Table 2

Distribution of Body Anthropometric and Ocular Parameters

\begin{tabular}{|lllll|}
\hline & Control & HTG & NTG & p-value \\
\hline Mean Age (years) & $53.8 \pm 15.7$ & $61.9 \pm 9.9$ & $54.8 \pm 11.9$ & 0.028 \\
Body Mass Index $\left(\mathrm{kg} / \mathrm{m}^{2}\right)$ & $25.53 \pm 4.56$ & $26.67 \pm 4.98$ & $24.48 \pm 4.88$ & 0.207 \\
Mean Decimal BCVA & $1.03 \pm 0.38$ & $1.07 \pm 0.35$ & $0.91 \pm 0.30$ & 0.154 \\
Mean VCDR & $0.36 \pm 0.09$ & $0.80 \pm 0.15$ & $0.74 \pm 0.08$ & $<0.001$ \\
Mean current IOP $(\mathrm{mmHg})$ & $13.6 \pm 1.5$ & $19.0 \pm 5.5$ & $13.0 \pm 2.5$ & $<0.001$ \\
\hline BCVA: Best-corrected Visual Acuity & & & \\
\hline VCDR: Vertical Cup-Disc Ratio & & & \\
\hline IOP: Intraocular pressure & & & & \\
\hline
\end{tabular}


Table 3

Reported Non-ocular Co-morbidities and Related Medications Use

\begin{tabular}{|lllll|}
\hline & Control & HTG & NTG & p-value \\
\hline Non-ocular comorbidity & 9 & 15 & 7 & 0.085 \\
Systemic hypertension & 0 & 1 & 3 & 0.089 \\
Others & 20 & 14 & 20 & 0.832 \\
None & 1 & 8 & 3 & \\
Systemic Medications & 1 & 3 & 3 & \\
Calcium channel blocker & 3 & 2 & 0 & \\
Diuretic & 0 & 1 & 4 & \\
ACE Inhibitor & & 21 & 6 & \\
Others & & 0 & 3 & \\
Anti-glaucoma Medications & & 17 & 5 & \\
Timolol & & 7 & 1 & \\
Betaxolol & & 2 & 1 & \\
Latanoprost & 5 & 0 & \\
Brimonidine & & & & \\
Dorzolamide & & & \\
Acetazolamide & & & & \\
ACE Inhibitor: Angiotensin-converting enzyme inhibitor & \\
\hline
\end{tabular}


Baseline Cardiovascular Profile

\begin{tabular}{|c|c|c|c|c|}
\hline Cardiovascular Parameters & $\begin{array}{l}\text { Control } \\
(n=30)\end{array}$ & $\begin{array}{l}\text { HTG } \\
(n=31)\end{array}$ & $\begin{array}{l}\text { NTG } \\
(n=31)\end{array}$ & $\begin{array}{l}\text { ANOVA } \\
\text { p-value }\end{array}$ \\
\hline Systolic BP (mmHg) & $134.0 \pm 19.5$ & $138.2 \pm 16.4$ & $129.3 \pm 18.4$ & 0.163 \\
\hline Diastolic BP (mmHg) & $83.0 \pm 8.7$ & $82.6 \pm 10.0$ & $79.5 \pm 11.9$ & 0.352 \\
\hline Mean resting R-R interval (sec) & $0.91 \pm 0.13$ & $0.99 \pm 0.17$ & $0.95 \pm 0.14$ & 0.140 \\
\hline Resting R-R interval variability & $1.78 \pm 1.25$ & $1.57 \pm 0.73$ & $2.11 \pm 1.91$ & 0.367 \\
\hline P-wave duration (sec) & $0.10 \pm 0.02$ & $0.10 \pm 0.02$ & $0.11 \pm 0.03$ & 0.099 \\
\hline P-wave amplitude (mm) & $1.22 \pm 0.42$ & $1.21 \pm 0.37$ & $1.09 \pm 0.33$ & 0.327 \\
\hline PR interval (sec) & $0.15 \pm 0.03$ & $0.18 \pm 0.03$ & $0.18 \pm 0.04$ & $0.008^{*}$ \\
\hline QRS duration (sec) & $0.08 \pm 0.01$ & $0.08 \pm 0.03$ & $0.08 \pm 0.02$ & 0.392 \\
\hline Q-T interval (sec) & $0.37 \pm 0.03$ & $0.38 \pm 0.03$ & $0.36 \pm 0.03$ & 0.289 \\
\hline $\mathrm{Q}-\mathrm{T}_{\text {corrected }}(\mathrm{sec})$ & $0.08 \pm 0.01$ & $0.08 \pm 0.01$ & $0.07 \pm 0.01$ & 0.268 \\
\hline \multicolumn{5}{|l|}{${ }^{*} \mathrm{p}<0.05$} \\
\hline \multicolumn{5}{|c|}{$\begin{array}{l}\text { Tukey Post-hoc test on PR interval: HTG versus Control }=0.015^{\star} \text {; NTG versus Control }=0.023^{\star} \text {; Others } \\
\text { (not significant) }\end{array}$} \\
\hline \multicolumn{5}{|c|}{ SBP-Systolic blood pressure; DBP- Diastolic blood pressure } \\
\hline \multicolumn{5}{|c|}{$\begin{array}{l}. Q-T_{\text {corrected }}=\backslash \text { raisebox1ex } \$ Q-T_{\text {measured }} \$ / \backslash \text { raisebox }-1 \text { ex } \$ \sqrt{R-\text { Rinterval }} \$ \text { (Bazzet's } \\
\text { formula) }\end{array}$} \\
\hline
\end{tabular}


Table 5

Parasympathetic Cardiac Autonomic Function Tests

\begin{tabular}{|c|c|c|c|c|}
\hline & $\begin{array}{l}\text { Control } \\
(n=30)\end{array}$ & $\begin{array}{l}\text { HTG } \\
(n=31)\end{array}$ & $\begin{array}{l}\text { NTG } \\
(n=31)\end{array}$ & $\begin{array}{l}\text { ANOVA p- } \\
\text { value }\end{array}$ \\
\hline Heart Rate Response to Deep Breathing & $0.97 \pm$ & \multirow{2}{*}{$\begin{array}{l}1.09 \pm 0.17 \\
0.79 \pm 0.14\end{array}$} & $1.03 \pm 0.20$ & $0.037 \star$ \\
\hline Mean Expiration R-R Interval (sec) & & & $0.75 \pm 0.12$ & 0.276 \\
\hline Mean Inspiration R-R Interval (sec) & $\begin{array}{l}0.74 \pm \\
0.14\end{array}$ & \multirow[t]{2}{*}{$1.39 \pm 0.18$} & $1.39 \pm 0.30$ & 0.456 \\
\hline Expiration-Inspiration Ratio (E:I ratio) & $\begin{array}{l}1.32 \pm \\
0.19\end{array}$ & & & \\
\hline $\begin{array}{l}\text { Heart Rate Response to Valsalva } \\
\text { Maneuver }\end{array}$ & $\begin{array}{l}0.69 \pm \\
0.12\end{array}$ & \multirow[t]{2}{*}{$0.74 \pm 0.14$} & \multirow[t]{2}{*}{$0.69 \pm 0.13$} & 0.289 \\
\hline $\begin{array}{l}\text { Mean Shortest RRI during } 15 \mathrm{sec} \text { strain } \\
\text { (sec) }\end{array}$ & $\begin{array}{l}0.98 \pm \\
0.15\end{array}$ & & & \\
\hline $\begin{array}{l}\text { Mean Longest RRI } 20 \text { beats post-strain } \\
\text { (sec) }\end{array}$ & $\begin{array}{l}1.43 \pm \\
0.25\end{array}$ & \multirow{2}{*}{$\begin{array}{l}1.05 \pm 0.22 \\
1.45 \pm 0.31\end{array}$} & \multirow{2}{*}{$\begin{array}{l}1.11 \pm 0.22 \\
1.65 \pm 0.48\end{array}$} & $0.038^{*}$ \\
\hline Mean Valsalva Ratio (VR) & & & & $0.034^{\star}$ \\
\hline Heart Rate Response to Standing & $0.73 \pm 0.15$ & $0.84 \pm 0.18$ & \multirow{2}{*}{$\begin{array}{l}0.79 \pm \\
0.14\end{array}$} & $0.033^{\star}$ \\
\hline $\begin{array}{l}\text { Minimum R-R interval at or around 15th } \\
\text { beat (sec) }\end{array}$ & $0.80 \pm 0.14$ & $0.92 \pm 0.18$ & & $0.020^{\star}$ \\
\hline $\begin{array}{l}\text { Maximum R-R interval at or around 30th } \\
\text { beat (sec) } \\
\text { 30:15 ratio }\end{array}$ & $1.12 \pm 0.13$ & $1.11 \pm 0.30$ & $\begin{array}{l}1.08 \pm \\
0.12\end{array}$ & 0.596 \\
\hline $\begin{array}{l}\text { RRI: R-R Interval } \\
{ }^{*} \mathrm{p}<0.05\end{array}$ & & & & \\
\hline
\end{tabular}

\section{Discussion}

The physiological changes that occur within and around the optic nerve are central to its viability and function. Glaucoma, though common, is only substantially understood in the context of elevated intraocular pressure, but in the absence of IOP level above statistically normal levels, it largely remains obscure. The study evaluated how cardiac autonomic function might influence the development of glaucoma in the two major variants of open-angle glaucoma that cannot be explained by other physiological or anatomical abnormalities.

The difference in the mean age of the NTG group compared to the Control group was not statistically significant but both were significantly lower than high-tension primary open-angle glaucoma (HTG). This can be attributable to the age-matching of participants enrolled into normal-tension glaucoma (NTG) group versus Control which was not applied to the HTG group since the major risk factor of elevated IOP 
has been well highlighted in the literature. Similar to findings in this study, the literature on glaucoma in Africa and other developing countries has reported mean ages in the sixth and seventh decades for patients presenting with POAG including normal-tension glaucoma [14-17]. Meanwhile, Ajite et al, Majeed et al and Riccadonna et al reported an average age within the sixth decade of life in the NTG subset of primary glaucoma patients in their study [18-20] The older mean age of the HTG group attests to the epidemiological findings of the increasing prevalence of POAG with age and the fact that the chronicity of the disease often results in late presentation long after the actual onset of the disease among blacks. More often than not, NTG in individuals with little or no visual impairment is detected as incidental findings during routine eye screening or while an individual is being evaluated for an unrelated complaint.

The disease severity as assessed by the degree of optic disc cupping was significantly different between the glaucoma study groups and Control group while there was no difference in the best-corrected visual acuity. Expectedly, the mean IOP in the HTG was significantly higher than that of NTG and Control, while there was no significant difference between the IOP of NTG and Control. The majority of the subjects in the glaucoma groups were using topical anti-glaucoma medications particularly Timolol which is a betablocker and Brimonidine, an alpha agonist. Both of them are known to have chronotropic and hypotensive effects on the heart following significant systemic absorption [21, 22] However, Stewart et al did not find any statistically significant difference in the exercise heart rate and blood pressure of subjects placed on topical Timolol, Brimonidine, Timolol/Brimonidine combination and placebo as against systemically administered formulations [23]. The subjects in our study had administered their topical medications at least 2 hours before the conduct of the cardiac autonomic function tests. However, it is not clear if significant systemic absorption could have occurred and sustained with a single drop of medication of approximately $25-50 \mu \mathrm{L}$ with the conjunctival sac's capacity limited to just about $10 \mu \mathrm{L}$, to cause a significant cardiovascular effect. This study showed that while the baseline PR interval was significantly longer in the NTG and HTG groups compared to the control, there was no difference in the PR intervals of users and non-users of topical beta-blockers. Considering the pharmacodynamics and pharmacokinetics of topically administered eye medications and the minute amount of systemic absorption of $0.5 \%$ concentration of commercially available Timolol and Brimonidine [21-23], we believe that the topical medication would have little or no effect on the result of cardiac autonomic function tests by the time they were conducted.

The pattern of distribution of systemic comorbidities such as systemic hypertension and the use of systemic medications were not statistically significant. The concept that hypertension is due to a derangement of sympathetic and parasympathetic cardiovascular regulation is one of the most widely accredited and tested hypotheses in cardiovascular research. Although this hypothesis has found support in experimental models of hypertension, there is no similarly conclusive evidence in humans [24]. A considerable proportion of participants across the three study groups were hypertensive and on medications particularly calcium channel blockers. Just like many other previously published studies [2527], subjects with systemic hypertension were not excluded since such exclusion could alter the actual characteristics of glaucoma patients and introduce statistical bias of lower baseline values of some cardiovascular parameters such as blood pressure. Most of the anti-hypertensive medications used by 
participants enrolled in the study are not known to have significant cardiogenic effects that may significantly affect the cardiac autonomic response.[28] Besides, cardiac autonomic response postmedication does not remarkably differ from the pre-medication state following long-term antihypertensive use because of baroreflex reset after the initial reflex activation brought about by the unloading of arterial baroreceptors in response to an acute fall in blood pressure [24,29]. Exception to the baroreflex reset phenomenon has been demonstrated with centrally-acting agents, beta receptor blockers, blockers of the renin-angiotensin system, or mineralocorticoid receptor antagonists and to some extent, thiazides and short-acting calcium channel blockers [24], majority of which were exclusion criteria for this study.

The Valsalva ratio was significantly higher in the NTG group than in the HTG and control group in our study. This finding differ from that of Mapstone et al, Bojić et al and Khan et al[30-32]. The authors reported that the Valsalva ratio was significantly higher among control than POAG. However, they did not classify into high-tension and normal-tension glaucoma. Bojić et a/ reported that although significant difference existed with the Valsalva ratio, the average values continued to be within the normal range. These authors believed that the Valsalva manoeuvre test is more accurate than other cardiovascular tests in the definition of autonomic dysfunction in glaucoma subjects. They also suggested that probably glaucoma reflects a systemic disease, not only an eye disease. The mean Valsalva ratio for POAG reported in our study and the values reported by other authors for POAG were within Ewing's recommended normal range of 1.20 and above [33]. The mean Valsalva ratio of the NTG group in our study was higher than that reported by Ogunlade et al among healthy young Nigerian adults [34].

The significantly higher values in this study suggest that the NTG group has exaggerated parasympathetic autonomic response as a result of significantly longer post-strain RR interval indicating more intense poststrain bradycardia. Higher Valsalva ratio could have also occurred as a result of the excessive rise of heart rate (parasympathetic withdrawal and sympathetic activation) in the face of declining blood pressure during the strain or excessive relative post-strain reduction of heart rate (parasympathetic response) in response to the rapid overshoot of arterial blood pressure or a combination of the aforementioned. Khan reported a significantly lower Valsalva heart rate among NTG patients [35]. Our study demonstrated that the higher VR in NTG patients reflects exaggerated baroreceptors response as evidenced by the significantly reduced post-strain heart rate (Table 5).

Valsalva manoeuvre causes an increase in intrathoracic pressure, reduces venous cardiac return, and increases venous pressure resulting in a drop of arterial pressure during the strain phase [36]. Valsalva manoeuvre also causes a reduction in ocular blood flow and associated rapid surge in intraocular pressure far over the upper limit of the normal range have been recorded [35, 37, 38]. Krist et al reported a higher prevalence of activities or diseases that result in frequent, transient increase in intrathoracic and intraabdominal pressures in the medical history of patients with NTG (45\%) than among POAG $(11 \%)$ patients further highlighting the possible effect of Valsalva manoeuvre on the optic nerve head perfusion [39].

The retina is considered to have one of the highest oxygen-consumption per unit weight of all the tissues of the body, surpassing even that of the brain. Neurons including retinal ganglion cells, unlike glia, depend 
almost entirely on oxidative metabolism for their energy supply. Whereas glial cells can survive for long periods under anoxic conditions, neurons are the first cells to die when oxygen is lacking [40]. The high energy requirement and near-total dependency of retinal ganglion cells on oxidative metabolism make them extremely vulnerable to energy exhaustion and eventual functional failure [41]. The simultaneous reduction of ocular blood flow, the large increase in intraocular pressure and increase venous pressure in the uveal circulation and episcleral vessels during the Valsalva manoeuvre results in reduced ocular perfusion and oxygen supply to the neurons [37, 42]. Valsalva-like manoeuvres (VM) are performed frequently in daily life without knowing it, when moderately forceful attempted exhalation is made against a closed airway during many physiological and pathological conditions and activities, such as coughing, sneezing, laughing, straining, singing, vomiting, lifting heavy objects, playing wind instruments and obstructive sleep apnea [37, 39, 42-45].

The significantly higher Valsalva ratio in the NTG group in this study suggests that such individuals might have an inappropriate cardiovascular response to stimuli similar to the Valsalva manoeuvre they may be regularly exposed to, resulting in considerable bradycardia and intermittent hypoxic state within and around the optic nerve. This could result in repeated mild reperfusion injuries, oxidative stress, and apoptotic cell death with chronic retinal ganglion cell loss similar to high-tension primary open-angle glaucoma [46]. The findings of this study reinforced the vascular theory of glaucomatous optic neuropathy in NTG. The continued progression of optic nerve head damage reported in individuals with initially high-tension POAG despite clinically-controlled IOP might also be a result of underlying cardiac autonomic dysfunction [47].

The evidence suggesting increased parasympathetic activity among glaucoma patients in this study was further supported by the significantly prolonged mean resting PR interval in both the HTG and NTG groups compared to the control group (Table 4). The PR interval represents the atrioventricular conduction time modulated by the ANS which is prolonged or shortened by the parasympathetic and sympathetic divisions respectively [48]. When the conduction time through the atrioventricular node is delayed by increased parasympathetic stimulation or sympathetic withdrawal, it causes a prolonged PR interval. Since resting cardiac conduction is chiefly under the influence of parasympathetic regulation [49], then the relatively prolonged mean resting PR intervals of the HTG and NTG groups may likely be due to relative overstimulation by the parasympathetic system. Further evidence supporting increased parasympathetic stimulation was noted among the HTG with the significantly prolonged mean maximum RR intervals during the deep breathing test, mean minimum RR at/around the 15th beat and mean maximum RR interval at/around the 30th beat post-standing compared to the corresponding values of the control group (Table 5). Prolonged RR interval may therefore be a reason for concern in conditions and occupation that require prolonged period of expiratory effort.

Riccadonna et al reported that their 24-hour BP monitoring and heart rate monitoring study have suggested that NTG patients have abnormal autonomic modulation of cardiovascular responses during both night and day [20]. The degree of cardiac autonomic dysfunction was reported to be more marked in 
patients with more severe forms of glaucoma. However, the index study did find such a significant relationship.

In conclusion, this study established that there was increased cardiovascular parasympathetic activity in the NTG and HTG groups with possible implications for optic nerve blood flow.

\section{Declarations}

Funding: No funds, grant, or other support was received.

Conflict of interest: The authors have no relevant financial or non-financial interests to disclose.

Availability of data and materials: This has been deposited in a data repository.

https://data.mendeley.com/datasets/hv23rs8xg6/draft?a=f288d643-b893-4c26-bc5c-7bdccb045b90

Code availability: Not applicable

Compliance with Ethical Standard

Ethics approval: Approval was obtained from the Ethics and Research Committee of Obafemi Awolowo University Teaching Hospital, Ile-lfe, Nigeria (OAUTHC/ERC/2017/12/01) and the study was therefore performed in accordance with the ethical standards laid down in the 1964 Declaration of Helsinki and its later amendments. All participants gave their informed consent prior to their inclusion in the study.

Consent to Participate: Informed consent was obtained from all individual participants included in the study.

\section{References}

1. Tham Y-C, Li X, Wong TY et al (2014) Global Prevalence of Glaucoma and Projections of Glaucoma Burden through 2040: A Systematic Review and Meta-Analysis. Ophthalmology 121:2081-2090. https://doi.org/10.1016/j.ophtha.2014.05.013

2. Anderson DR (2011) Normal-tension glaucoma (Low-tension glaucoma). Indian J Ophthalmol 59(Suppl 1):S97-S101. https://doi.org/10.4103/0301-4738.73695

3. Gibbons CH, Cheshire WP, Fife TD (2014) Model Coverage Policy: Autonomic Testing. American Academy of Neurology

4. McDougal DH, Gamlin PD (2015) Autonomic control of the eye. Comprehensive Physiology 5:439473. https://doi.org/10.1002/cphy.c140014.Autonomic

5. Riva CE, Titze P, Hero M et al (1997) Choroidal blood flow during isometric exercises. Investigative Ophthalmology Visual Science 38:2338-2343

6. Choi J, Jeong J, Cho H, Kook MS (2006) Effect of Nocturnal Blood Pressure Reduction on Circadian Fluctuation of Mean Ocular Perfusion Pressure: A Risk Factor for Normal Tension Glaucoma. Invest 
Ophthalmol Vis Sci 47:831-836. https://doi.org/10.1167/iovs.05-1053

7. Quill B, Henry E, Simon E, Brien CJO (2015) Evaluation of the Effect of Hypercapnia on Vascular Function in Normal Tension Glaucoma. BioMed Research International 1-11

8. Gherghel D, Orgül S, Dubler B et al (1999) Is vascular regulation in the central retinal artery altered in persons with vasospasm? Arch Ophthalmol 117:1359-1362

9. Emre M (2004) Ocular blood flow alteration in glaucoma is related to systemic vascular dysregulation. Br J Ophthalmol 88:662-666. https://doi.org/10.1136/bjo.2003.032110

10. Banerjee A, Khurana I (2017) Altered autonomic balance in normal tension glaucoma. Asian Journal of Pharmaceutical Clinical Research 10:6-8

11. Kurysheva NI, Shlapak VN, Ryabova TY (2018) Heart rate variability in normal tension glaucoma. Medicine 97:e9744. https://doi.org/10.1097/MD.0000000000009744

12. Gasser P, Flammer J (1991) Blood-Cell Velocity in the Nailfold Capillaries of Patients with NormalTension and High-Tension Glaucoma. Am J Ophthalmol 111:585-588. https://doi.org/10.1016/S0002-9394(14)73703-1

13. Ewing DJ, Campbell IW, Clarke BF (1980) Assessment of Cardiovascular effects in Diabetic Autonomic Neuropathy and Prognostic implications. Ann Intern Med 92:308-311

14. Mafwiri M, Bowman RJC, Wood M, Kabiru J (2005) Primary Open-Angle Glaucoma Presentation at a Tertiary Unit in Africa: Intraocular Pressure Levels and Visual Status. Ophthalmic Epidemiol 12:299302. https://doi.org/10.1080/09286580500180572

15. Abdull MM, Gilbert CC, Evans J (2015) Primary open angle glaucoma in northern Nigeria: stage at presentation and acceptance of treatment. BMC Ophthalmology 15:111. https://doi.org/10.1186/s12886-015-0097-9

16. Olajide O, Onabolu O, Jagun 0 et al (2017) Spectrum of Glaucoma Presentation in a Suburban Teaching Hospital in South Western Nigeria. Health Science Journal 10:1-4. https://doi.org/10.21767/1791-809X.1000466

17. Olawoye O, Tarella S (2018) Spectrum of Glaucoma Presentation in a Nigerian Tertiary Hospital. Nigerian Journal of Ophthalmology 22:1-15. https://doi.org/10.4103/0189-9171.142747

18. Ajite KO, Fadamiro CO, Ajayi IA et al (2016) Demographic Characteristics of Normal Tension Glaucoma Seen in a Suburban Tertiary Hospital. International Journal of Ophthalmology Eye Science 4:215-219. https://doi.org/10.19070/2332-290X-1600044

19. Majeed F, Tauheed S, Aamir IS et al (2007) Frequency of Normal-Tension Glaucoma in Suspected Cases of Primary Open Angle Glaucoma. Pakistan Journal of Ophthalmology 2:192-197

20. Riccadonna M, Covi G, Pancera P et al (2003) Autonomic System Activity and 24-Hour Blood Pressure Variations in Subjects with Normal- and High-Tension Glaucoma. J Glaucoma 12:156-163. https://doi.org/10.1097/00061198-200304000-00011

21. Nieminen T, Lehtimäki T, Mäenpää J et al (2007) Ophthalmic timolol: Plasma concentration and systemic cardiopulmonary effects. Scand J Clin Lab Invest 67:237-245. https://doi.org/10.1080/00365510601034736 
22. Farkouh A, Frigo P, Czejka M (2016) Systemic side effects of eye drops: a pharmacokinetic perspective. Clinical Ophthalmology (Auckland NZ) 10:2433-2441.

https://doi.org/10.2147/OPTH.S118409

23. Stewart WC, Stewart JA, Jackson AL (2002) Cardiovascular effects of timolol maleate, brimonidine or brimonidine/timolol maleate in concomitant therapy. Acta Ophthalmol Scand 80:277-281. https://doi.org/10.1034/j.1600-0420.2002.800309.x

24. Mancia G, Grassi G (2014) The autonomic nervous system and hypertension. Circ Res 114:18041814. https://doi.org/10.1161/CIRCRESAHA.114.302524

25. Gherghel D, Hosking SL, Armstrong R, Cunliffe IA (2007) Autonomic dysfunction in unselected and untreated primary open angle glaucoma patients: a pilot study. Ophthalmic Physiol Opt 27:336-341. https://doi.org/10.1111/j.1475-1313.2007.00485.x

26. Wierzbowska J, Wierzbowski R, Wierzbowska J et al (2012) Cardiac autonomic dysfunction in patients with normal tension glaucoma: 24 -h heart rate and blood pressure variability analysis. $\mathrm{Br} \mathrm{J}$ Ophthalmol 96:624-628. https://doi.org/10.1136/bjophthalmol-2011-300945

27. Mroczkowska S, Benavente-Perez A, Negi A et al (2013) Primary Open-Angle Glaucoma vs NormalTension Glaucoma: The Vascular Perspective. JAMA Ophthalmology 131:36-43. https://doi.org/10.1001/2013.jamaophthalmol.1

28. Grassi G (2016) Sympathomodulatory Effects of Antihypertensive Drug Treatment. Am J Hypertens 29:665-675. https://doi.org/10.1093/ajh/hpw012

29. Grassi G (2000) Sympathoexcitatory responses to the acute blood pressure fall induced by central or peripheral antihypertensive drugs. Am J Hypertens 13:29-34. https://doi.org/10.1016/S08957061(99)00150-8

30. Mapstone R, Clark CV (1985) The prevalence of autonomic neuropathy in glaucoma. Transactions of the Ophthalmological Societies of the United Kingdom 104:265-269

31. Bojić L, Čagalj S, Račić G, Karaman-Kraljević K (1993) Cardiovascular reflex testing and pupil cycle time in open-angle glaucoma. Ophthalmologica 206:158-161. https://doi.org/10.1159/000310383

32. Khan MM, Ghosh S, Bera C (2015) Study of Autonomic Activities in Primary Open Angle Glaucoma. Journal of Evolution of Medical Dental Sciences 4:16865-16870. https://doi.org/10.14260/jemds/2015/2536

33. Ewing DJ, Burt AA, Campbell IW, Clarke BF (1973) Vascular Reflexes in Diabetic Autonomic Neuropathy. The Lancet 302:1354-1356. https://doi.org/10.1016/S0140-6736(73)93323-0

34. Ogunlade O, Ayoka AO, Akintomide A et al (2015) Non-Invasive Assessment of Cardiac Autonomic Functions in Healthy Young Adults in Ile-Ife, South-Western Nigeria. Int J Clin Cardiol 2:036

35. Khan JC (2002) Pulsatile ocular blood flow: the effect of the Valsalva manoeuvre in open angle and normal tension glaucoma: a case report and prospective study. Br J Ophthalmol 86:1089-1092. https://doi.org/10.1136/bjo.86.10.1089

36. Begum S, Razak A (2015) Valsalva ratio: a measure of stress in first year medical students. International Journal of Research in Medical Sciences 3:1599-1604 
37. Schuman JS, Massicotte EC, Connolly S et al (2000) Increased Intraocular Pressure and Visual Field Defects in High Resistance Wind Instrument Players. Ophthalmology 107:127-133

38. Bussel II, Aref AA (2014) Dietary factors and the risk of glaucoma: a review. Therapeutic Advances in Chronic Disease 5:188-194. https://doi.org/10.1177/2040622314530181

39. Krist D, Cursiefen C, Jünemann A (2001) Transient intrathoracic and -abdominal pressure elevation in the history of 64 patients with normal-tension glaucoma. Klin Monatsbl Augenheilkd 218:209-213. https://doi.org/10.1055/s-2001-14915

40. Wong-Riley M (2010) Energy metabolism of the visual system. Eye Brain 2:99-116

41. Morgan JE (2004) Circulation and axonal transport in the optic nerve. Eye 18:1089-1095. https://doi.org/10.1038/sj.eye.6701574

42. Palamar M, Dag MY, Yagci A (2015) The effects of Valsalva manoeuvre on Ocular Response Analyzer measurements. Clinical Experimental Optometry 98:447-450. https://doi.org/10.1111/cxo.12303

43. van Meurs JC, van den Bosch WA (1993) Suprachoroidal Hemorrhage Following a Valsalva Maneuver. Arch Ophthalmol 111:1025-1026

44. Vieira GM, Oliveira HB, De Andrade DT et al (2006) Intraocular pressure variation during weight lifting. Arch Ophthalmol 124:1251-1254. https://doi.org/10.1001/archopht.124.9.1251

45. Macey PM, Kumar R, Woo MA et al (2013) Heart Rate Responses to Autonomic Challenges in Obstructive Sleep Apnea. PLoS ONE 8:e76631. https://doi.org/10.1371/journal.pone.0076631

46. Flammer J, Mozaffarieh M (2008) Autoregulation, a balancing act between supply and demand. Can J Ophthalmol 43:317-321. https://doi.org/10.3129/i08-056

47. Collignon N, Dewe W, Guillaume S, Collignon-Brach J (1998) Ambulatory blood pressure monitoring in glaucoma patients. The nocturnal systolic dip and its relationship with disease progression. Int Ophthalmol 22:19-25. https://doi.org/10.1023/A:1006113109864

48. Leffler CT, Saul JP, Cohen RJ (1994) Rate-Related and Autonomic Effects on Atrioventricular Conduction Assessed Through Beat-to-Beat PR Interval and Cycle Length Variahility. Journal of Cardivascular Electrophysiology 5:2-15

49. Sheridan E, Heneghan C, O'Malley MO et al (2001) Characterization of autonomic nervous influences on PR and RR intervals in the electrocardiogram. In: 23rd Annual International Conference of the IEEE Engineering in Medicine and Biology Society. pp 540-543 